\title{
Dependence of the Size of Nanoparticles of Lead Sulfide PbS on the Chemical Affinity of Its Formation Reaction
}

\author{
N. S. Kozhevnikova ${ }^{a, b}$, A. A. Uritskaya ${ }^{b}$, and Corresponding Member of the RAS A. A. Rempel ${ }^{a, b}$ \\ Received May 6, 2013
}

DOI: $10.1134 / \mathrm{S} 0012501613110031$

The existing approaches to synthesizing high-quality nanocrystals, in particular, quantum dots at high fluorescence yield and narrow size scatter reduce to two main methods. The most widely used and most studied of them is high-temperature organometallic synthesis. This method was proposed by Bawendi et al. in 1993 [1] and consists in producing inorganic nanoparticles in organic solvents. An alternative to organometallic synthesis is an experimentally simpler synthesis method called one-pot method. This method is currently widely used in organic synthesis but is becoming more and more popular for synthesizing inorganic compounds in the nanocrystalline state, e.g., oxides [2], core@shell structures based on pure metals [3] and metal chalcogenides [4], and semiconductor nanocrystals and quantum dots [5]. Among one-pot methods is chemical condensation or chemical precipitation from solutions, by which nanoparticles can be synthesized directly in the aqueous medium - this is a necessary condition of using these nanoparticles in biology and medicine.

In producing nanoparticles of predetermined morphology (size, shape) by chemical precipitation from aqueous solutions, two stages are critical: the stage of the primary chemical interaction to form a precipitatesolution system, at which nuclei emerge and grow, and the stage of aging of the system because of secondary processes of interaction of the precipitate and the solution. The purpose of this work was to study how the initial conditions of the chemical precipitation (namely, the chemical affinity $A$ of the reaction and the relative supersaturation) affect the size of nanoparticles forming at both stages of chemical precipitation.

The object of synthesis and investigation was the narrow-band semiconductor lead sulfide $\mathrm{PbS}$ with important quantum properties in the IR spectral range [6]. Lead sulfide in the equilibrium state has a cubic structure of the $B 1$ type $(\mathrm{NaCl}$, space group $F m-3 m$ ). Lead sulfide was chosen because of its practical impor-

\footnotetext{
${ }^{a}$ Institute of Solid-State Chemistry, Ural Branch, Russian Academy of Sciences, ul. Pervomaiskaya 91, Yekaterinburg, 620990 Russia

${ }^{b}$ Yeltsin Ural Federal University, ul. Mira 19, Yekaterinburg, 620002 Russia
}

tance for the nanoindustry, including nanoelectronics and nanomedicine, in particular, for creating lasers with elevated radiating power, using as thermoelectric materials for efficient direct and reverse heat conversion to electricity, and applying in medical histological diagnosis, monitoring biological processes in living organisms, multicolor representation of genome structure, etc.

\section{EXPERIMENTAL \\ Calculation of Chemical Affinity}

The chemical precipitation of $\mathrm{PbS}$ was performed in a closed system at constant temperature and pressure. In such systems, the state function $A$ called chemical affinity of reaction is more than or equal to zero: $A \geq 0$ [7]. In this relation, the inequality corresponds to a spontaneously occurring reaction and the equality $A=0$ means equilibrium. The function $A$ is independent of the kind of the process under consideration and is determined only by the initial and final states of the system. For a spontaneous reaction proceeding from left to right (e.g., $\mathrm{Pb}^{2+}+\mathrm{S}^{2-} \rightarrow \mathrm{PbS}$ ) at constant pressure and temperature, we have [7]

$$
A_{p, T}=-\Delta G_{p, T}=R T \ln \frac{K(T, p)}{\prod_{i}\left(c_{i} \gamma_{i}\right)^{v_{i}}}>0
$$

where $K(T, p)$ is the equilibrium constant for the process under consideration; $c_{i}$ is an arbitrary, e.g., initial, molar concentration of component $i$; $\gamma_{i}$ is the activity coefficient of component $i$; and $v_{i}$ is the stoichiometric coefficient.

\section{Synthesis}

In this work, $\mathrm{PbS}$ particles were produced by homogeneous and heterogeneous methods of chemical precipitation from aqueous solutions, which are based on the interaction of soluble lead compounds with sulfidizing agents. The fundamental difference of the homogeneous method from the heterogeneous one is that a precipitant containing the ion $\mathrm{S}^{2-}$ is not added to the solution containing the ions $\mathrm{Pb}^{2+}$ to be precipitated but is slowly and gradually forms by reactions in solution. 


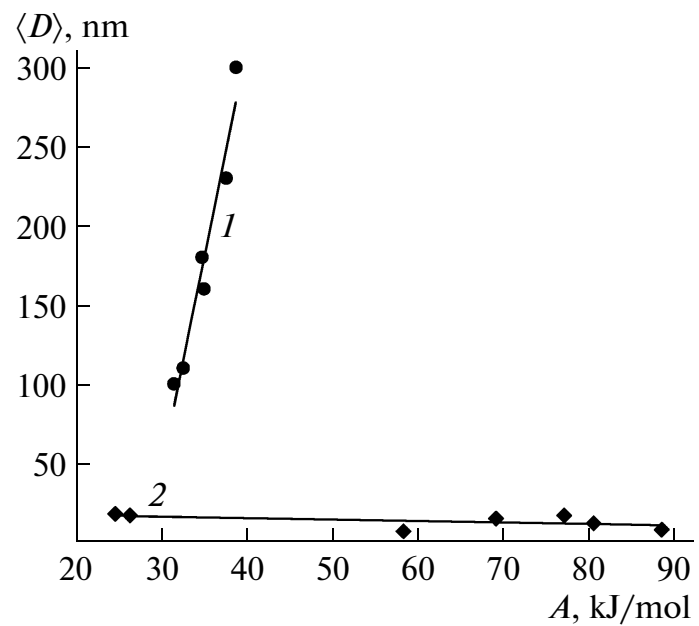

Fig. 1. Dependence of the size $\langle D\rangle$ of $\mathrm{PbS}$ nanoparticles on the chemical affinity $A$ of their formation reaction in the (1) homogeneous and (2) heterogeneous precipitation. The size $\langle D\rangle$ was determined immediately after the synthesis.

In the homogeneous method of chemical precipitation, $\mathrm{PbS}$ was synthesized from an aqueous solution of lead acetate $\mathrm{Pb}\left(\mathrm{CH}_{3} \mathrm{COO}\right)_{2}(0.005-0.010 \mathrm{M})$ and thiourea $\left(\mathrm{NH}_{2}\right)_{2} \mathrm{CS}(0.025-0.050 \mathrm{M})$ in the presence of sodium citrate $\mathrm{Na}_{3} \mathrm{C}_{6} \mathrm{H}_{5} \mathrm{O}_{7}$ and sodium hydroxide $\mathrm{NaOH}$ at $\mathrm{pH}$ 12. Initially, the reaction of $\mathrm{Pb}\left(\mathrm{CH}_{3} \mathrm{COO}\right)_{2}$ with $\mathrm{Na}_{3} \mathrm{C}_{6} \mathrm{H}_{5} \mathrm{O}_{7}$ gave the complex lead salt $\mathrm{Pb}(\mathrm{OH}) \mathrm{Cit}^{2-}$, and the further precipitation occurred by the reaction

$$
\begin{aligned}
& \mathrm{Pb}(\mathrm{OH}) \mathrm{Cit}^{2-}+\left(\mathrm{NH}_{2}\right)_{2} \mathrm{CS}+\mathrm{OH}^{-} \\
& =\mathrm{PbS}+\mathrm{Cit}^{3-}+\mathrm{H}_{2} \mathrm{NCN}+2 \mathrm{H}_{2} \mathrm{O} .
\end{aligned}
$$

To calculate $A$ by formula (1) at the initial moment of the process, it is necessary to make a thermodynamic analysis of the initial conditions. Taking into account the reversibility of the hydrolytic decomposition of $\left(\mathrm{NH}_{2}\right)_{2} \mathrm{CS}$ in aqueous alkaline solutions [6], we performed a thermodynamic analysis of the equilibrium existence of lead sulfide, lead hydroxide, and other intermediate products of the precipitation reaction as shown previously $[9,10]$. Based on the calculation results, we made a well-founded choice of the $\mathrm{pH}$ range and the concentrations of the components of the system

$$
\mathrm{Pb}^{2+}-\mathrm{Cit}^{3-}-\mathrm{OH}^{-}-\mathrm{N}_{2} \mathrm{H}_{4} \mathrm{CS}-\mathrm{H}_{2} \mathrm{O} \text {, }
$$

that were necessary for varying $A$ of the reaction of the formation of $\mathrm{PbS}$ nanoparticles over a wide range.

In the heterogeneous method of chemical precipitation, $\mathrm{PbS}$ was synthesized [11] by mixing stoichiometric amounts of aqueous solutions of lead acetate and sodium sulfide by the reaction

$\mathrm{Pb}\left(\mathrm{CH}_{3} \mathrm{COO}\right)_{2}+\mathrm{Na}_{2} \mathrm{~S}=\mathrm{PbS}+2 \mathrm{NaCH}_{3} \mathrm{COO}$.

In the interaction of the aqueous solutions of $\mathrm{Pb}\left(\mathrm{CH}_{3} \mathrm{COO}\right)_{2}(0.025-0.250 \mathrm{M})$ and $\mathrm{Na}_{2} \mathrm{~S}(0.025-$ $0.050 \mathrm{M})$, along with the expected product $(\mathrm{PbS}$

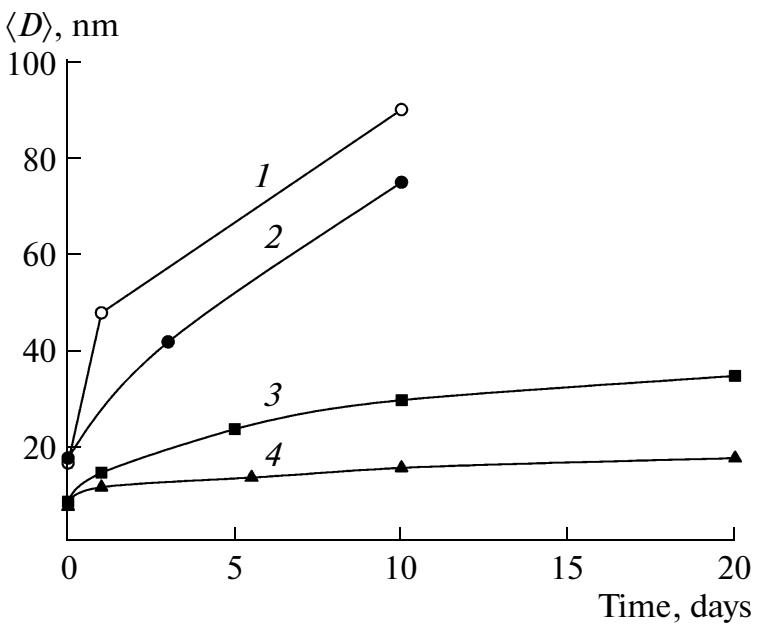

Fig. 2. Dependence of the size $\langle D\rangle$ of $\mathrm{PbS}$ nanoparticles on their residence time in solution in the heterogeneous precipitation at $A=$ (1) 26.28 , (2) 24.56 , (3) 77.06 , and (4) $88.47 \mathrm{~kJ} / \mathrm{mol}$. The $\mathrm{PbS}$ precipitate-solution systems were stored at room temperature.

nanoparticles), hydrolysis products may also form, which was observed experimentally [11]. It is difficult to theoretically predict a priori what hydrolysis reactions will occur in this system and what conversions will be reached. Therefore, for inhibiting such reactions, citrate or trilonate ions were introduced into the $\mathrm{Pb}\left(\mathrm{CH}_{3} \mathrm{COO}\right)_{2}$ solution by adding an aqueous solution of sodium salt $\mathrm{Na}_{3} \mathrm{C}_{6} \mathrm{H}_{5} \mathrm{O}_{7}$ or $\mathrm{Na}_{2} \mathrm{C}_{10} \mathrm{H}_{14} \mathrm{O}_{8} \mathrm{~N}_{2}$, respectively. The synthesis was performed under standard conditions ( $298 \mathrm{~K}, 1 \mathrm{~atm})$.

Because the chemical precipitation of $\mathrm{PbS}$ was performed at different concentrations of the initial components, the $A$ value was varied over a wide range. The chemical precipitation of $\mathrm{PbS}$ was carried out at constant temperature and $\mathrm{pH}$, and also at the same sequence and rate of mixing of reactants. The $A$ value was calculated for each reaction of the formation of $\mathrm{PbS}$ particles in aqueous solution by methods of equilibrium thermodynamics of electrolyte solutions. It was considered that the reaction occurs in the system that is in partial equilibrium. Because the precipitation was conducted from diluted solutions, the activity coefficients of the components were assumed to be unities. In the heterogeneous and homogeneous precipitations, $A$ was varied within the ranges from 20.57 to 88.47 and from 31.42 to $38.68 \mathrm{~kJ} / \mathrm{mol}$, respectively.

The crystal structure and average size of $\mathrm{PbS}$ particles were determined by X-ray powder diffraction by analogy with published cases $[10,12]$. The results showed that, in this work, we obtained nanocrystalline lead sulfide powders with an average particle size of 8 to $300 \mathrm{~nm}$. The observed large broadening of diffraction reflections is mainly due to small particle size. All the $\mathrm{PbS}$ nanopowders are characterized by the same set of diffraction reflections, which corresponds to the cubic structure $B 1$. 


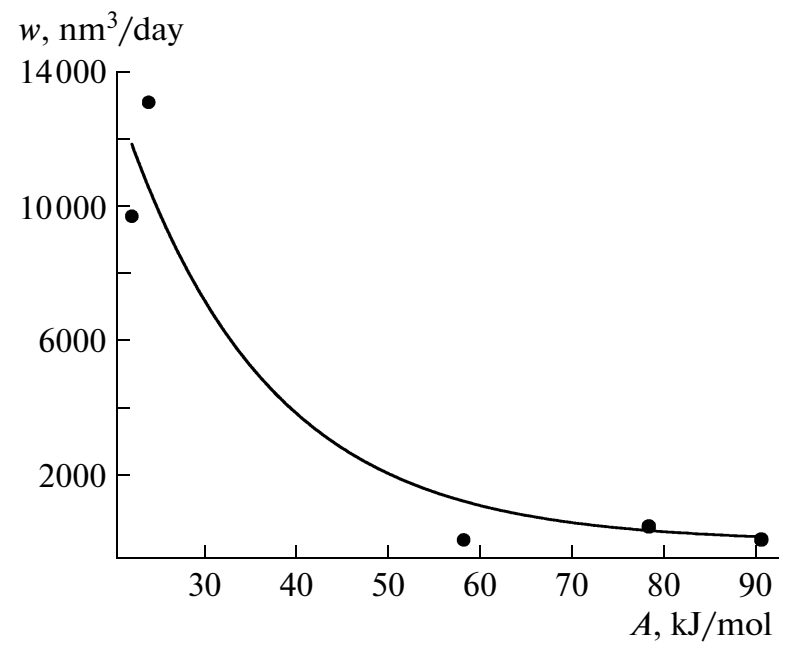

Fig. 3. Dependence of the rate $w$ of growth of $\mathrm{PbS}$ nanoparticles on $A$ in the heterogeneous precipitation. The points represent experimental data; the curve is the approximation by an exponential function of the form $w(A)=k \exp \left(-A / A_{0}\right)$.

\section{RESULTS AND DISCUSSION}

Study of the stage of the primary chemical interaction to form a precipitate-solution system. The set of experiments on the heterogeneous precipitation of slightly soluble hydrophobic $\mathrm{PbS}$ nanoparticles from aqueous solutions showed that the size of primary particles insignificantly decreases with increasing $A$ and, correspondingly, with increasing relative supersaturation over a wide range. The average size of $\mathrm{PbS}$ nanoparticles is $\langle D\rangle=18 \pm 2 \mathrm{~nm}$ at $A=24.56-26.28 \mathrm{~kJ} / \mathrm{mol}$ and $\langle D\rangle=10 \pm 2 \mathrm{~nm}$ at $A=80.49-88.47 \mathrm{~kJ} / \mathrm{mol}$ (Fig. 1). Conversely, in the homogeneous precipitation, the $\mathrm{PbS}$ particle size considerably increases with insignificantly increasing $A$ : from $\langle D\rangle=90 \pm 10 \mathrm{~nm}$ at $A=$ $31.42 \mathrm{~kJ} / \mathrm{mol}$ to $\langle D\rangle=300 \pm 10 \mathrm{~nm}$ at $A=38.68 \mathrm{~kJ} / \mathrm{mol}$.

The morphology of precipitate particles is known to be determined by the ratio between the rate of the formation of crystal nuclei and the rate of their growth. In von Weimarn's classical precipitation theory [13], the nucleation rate is directly dependent on the supersaturation and, correspondingly, $A$ : all other conditions being equal, the higher the nucleation rate, the higher the supersaturation of the initial solution. It should be taken into account that, according to Volmer's quantitative theory of crystal nucleation $[14,15]$, increasing supersaturation causes an increase both in the nucleation rate, and in the nuclei growth rate; however, the latter depends on supersaturation less strongly. According to the existing notions, with increasing supersaturation of a solution, smaller and smaller nuclei become stable in it, because of which their nucleation rate is higher and the size of the grown particles is smaller.

Thus, in the heterogeneous chemical precipitation, the formation of $\mathrm{PbS}$ nanoparticles from aqueous solutions obeys the classical precipitation theory and the Weimarn-Haber precipitation rule, whereas, in the homogeneous precipitation, there is an abnormal dependence between the size of $\mathrm{PbS}$ nanoparticles and the chemical affinity $A$ of their formation reaction: the size of $\mathrm{PbS}$ nanoparticles is directly proportional to $A$. This can be explained as follows.

The limiting stage of the formation of $\mathrm{PbS}$ in aqueous solutions of $\left(\mathrm{NH}_{2}\right)_{2} \mathrm{CS}$ (in the homogeneous precipitation) is the $\mathrm{N}_{2} \mathrm{H}_{4} \mathrm{CS}$ hydrolysis to form sulfide and hydrosulfide ions [8]. This reaction has quite a long induction period, and $\mathrm{PbS}$ forms at a noticeably lower rate than in the case of using a $\mathrm{Na}_{2} \mathrm{~S}$ solution containing $\mathrm{S}^{2-}$ and $\mathrm{HS}^{-}$ions. For example, at room temperature (in the heterogeneous participation), $\mathrm{PbS}$ forms as early as the first seconds, whereas, in the homogeneous precipitation, the first $\mathrm{PbS}$ particles emerge in approximately 60 min after mixing the reactants. Because of this, the supersaturation is low and primary crystallization nuclei are relatively few. As a result, the hydrolysis of the precipitant $\left(\mathrm{NH}_{2}\right)_{2} \mathrm{CS}$ leads not so much to the emergence of new PbS crystallization nuclei as to an increase in the size of the already forming nuclei. The nuclei growth rate is directly proportional to the initial concentrations of $\mathrm{Pb}\left(\mathrm{CH}_{3} \mathrm{COO}\right)_{2}$ and $\mathrm{N}_{2} \mathrm{H}_{4} \mathrm{CS}$, i.e., to $A$.

The results obtained suggest that, in the homogeneous method of chemical precipitation, nuclei grow much faster than they emerge. This leads to producing larger particles, the size of which increases with increasing $A$.

Study of the stage of aging of the precipitate-solution system. The observations of the spontaneous change in the size of nanoparticles in contact with solution demonstrated that, at high $A$ (above $75 \mathrm{~kJ} / \mathrm{mol}$ ), nanoparticles hardly grow, whereas at low $A$ (below $40 \mathrm{~kJ} / \mathrm{mol}$ ), nanoparticles transform to submicronsized $(\sim 100 \mathrm{~nm})$ particles (Fig. 2). For example, at $A=$ $88.47 \mathrm{~kJ} / \mathrm{mol},\langle D\rangle$ for 10 days only doubles: from $8 \pm 1$ to $16 \pm 2 \mathrm{~nm}$, whereas, at $A=26.28 \mathrm{~kJ} / \mathrm{mol},\langle D\rangle$ changes for the same time by a factor of 4.5 from $17 \pm 1$ to $90 \pm$ $10 \mathrm{~nm}$.

It was also detected (Fig. 3) that the rate $w$ of growth of nanoparticles in contact with solution is inversely proportional to $A$. The identified dependence of the nanoparticle growth rate on the chemical affinity $A$ is described by an exponential function of the form $w(A)=k \exp \left(-A / A_{0}\right)$, where $w=\Delta V_{\mathrm{PbS}} / \Delta \tau$ is the nanoparticle growth rate, $\Delta V_{\mathrm{PbS}}$ is the change in the volume of a $\mathrm{PbS}$ nanoparticle in time $\Delta \tau, k=$ $62217 \mathrm{~nm}^{3} /$ day, and $A_{0}=14.8 \mathrm{~kJ} / \mathrm{mol}$. This dependence was derived under certain assumptions of the shape of particles (particles were taken to be spherical) and the growth laws (all the particle surface elements were believed to be identically efficient growth regions).

These experimental data suggested that, at high $A$ (above $75 \mathrm{~kJ} / \mathrm{mol}$ ), the physical aging of the $\mathrm{PbS}$ precipitate-solution system occurs by a recrystallization 
mechanism, by which, first of all, the crystal lattice loses excess surface defects by dissolving more defective regions on the particle surface, whereas the size of primary particles remains unchanged or changes hardly.

At low $A$ (below $40 \mathrm{~kJ} / \mathrm{mol}$ ), the $\mathrm{PbS}$ precipitatesolution system ages by the Ostwald ripening mechanism [15]. By analyzing the Ostwald ripening equation, it was concluded that, in the $\mathrm{PbS}$ precipitatesolution system, there is an active growth of particles, with larger particles growing by dissolving smaller ones, as was observed in our experiments.

The Ostwald ripening does not occur in highly agglomerated and coagulated precipitates, such as those obtained at $A>75 \mathrm{~kJ} / \mathrm{mol}$.

Thus, we detected the following dependence. In the heterogeneous precipitation of $\mathrm{PbS}$ nanoparticles, with increasing precipitation time (lifetime of the precipitate-solution system), the chemical affinity $A$ corresponding to the maximal particle size decreases and the maximal particle size increases.

We determined the dependence of the chemical composition of the $\mathrm{PbS}$ precipitate and the size of its particles on the method of chemical precipitation and gave recommendations on the production of $\mathrm{PbS}$ nanoparticles of predetermined size and chemical composition $\mathrm{PbS}$. Based on this dependence, the following conclusions can be made: $\mathrm{PbS}$ nanoparticles should be obtained by heterogeneous precipitation at a chemical affinity of the reaction of less than $40 \mathrm{~kJ} / \mathrm{mol}$ at a stoichiometric ratio between the reactants while varying the lifetime of the $\mathrm{PbS}$ nanoparticles-solution system.

Thus, by the example of the chemical precipitation of $\mathrm{PbS}$ nanoparticles, we studied the effect of the stage of the primary chemical interaction to form a precipitate-solution system and the stage of aging of the system on the size of the forming nanoparticles. We showed that, in the heterogeneous chemical precipitation, the formation of slightly soluble hydrophobic $\mathrm{PbS}$ nanoparticles from aqueous solutions obeys the classical precipitation theory: the particle size increases with decreasing supersaturation. In the homogeneous precipitation, there is an abnormal dependence between the size of $\mathrm{PbS}$ nanoparticles and the chemical affinity $A$ of their formation reaction: the size of $\mathrm{PbS}$ nanoparticles is directly proportional to $A$.

The study of the stage of aging of the PbS precipitate-solution system showed that the rate of growth of nanoparticles in contact with solution is inversely proportional to $A$. In the heterogeneous precipitation of nanoparticles, with increasing precipitation lifetime of this system, the chemical affinity corresponding to the maximal particle size decreases and the maximal particle size increases. At high chemical affinity $A$ (above $75 \mathrm{~kJ} / \mathrm{mol}$ ), the physical aging of the $\mathrm{PbS}$ precipitatesolution system occurs by a recrystallization mecha- nism, and at low $A$ (below $40 \mathrm{~kJ} / \mathrm{mol}$ ), it occurs by the Ostwald ripening mechanism.

\section{ACKNOWLEDGMENTS}

We thank S.I. Sadovnikov for his help in processing the results of the X-ray powder diffraction experiment.

This work was supported by the Russian Foundation for Basic Research (project no. 11-08-00314) and the Ural Branch of the Russian Academy of Sciences (project no. 12-P-234-2003) according to Program no. 24 of the Presidium of the Russian Academy of Sciences "Fundamentals of Technologies of Nanostructures and Nanomaterials."

\section{REFERENCES}

1. Murray, C.B., Norris, D.J., and Bawendi, M.G., J. Am. Chem. Soc., 1993, vol. 115, no. 19, pp. 8706-8715.

2. Zeng, Y., Hao, R., Xing, B., Hou, Y., and Xu, Z., Chem. Commun., 2010, vol. 46, no. 22, pp. 3920-3922.

3. Hongchen Dong H., Zhu, M., Yoon, J.A., Gao, H., Jin, R., and Matyjaszewski, K., J. Am. Chem. Soc., 2008, vol. 130, no. 39, pp. 12852-12853.

4. Gu, Z., Zou, L., Fang, Z., Zhu, W., and Zhong, X., Nanotechnology, 2008, vol. 19, no. 13, p. 7.

5. Tang, A., Qu, S., Li, K., Hou, Y., Teng, F., Cao, J., Wang, Y., and Wang, Z., Nanotechnology, 2010, vol. 21, no. 28 , p. 9 .

6. Wise, F.W., Acc. Chem. Res., 2000, vol. 33, no. 11, pp. 773-780.

7. Prigogine, I. and Defay, R., Chemical Thermodynamics, Longmans-Green, 1954. Translated under the title Khimicheskaya termodinamika, Novosibirsk: Nauka, 1966.

8. Kitaev, G.A. and Romanov, I.T., Izv. Vyssh. Uchebn. Zaved., Khim. Khim. Tekhnol., 1974, vol. 17, no. 9, pp. 1427-1428.

9. Belova, N.S., Uritskaya, A.A., and Kitaev, G.A., $Z h$. Prikl. Khim., 2002, vol. 75, no. 10, pp. 1598-1601.

10. Rempel, A.A., Kozhevnikova, N.S., Leenaers, A.J.G., and Berghe, S., J. Cryst. Growth, 2005, vol. 280, nos. $1 / 2$, pp. $300-308$.

11. Kozhevnikova, N.S., Sadovnikov, S.I., and Rempel', A.A., Zh. Obshch. Khim., 2011, vol. 81, no. 10, pp. 1608-1613.

12. Kozhevnikova, N.S., Kurlov, A.S., Uritskaya, A.A., and Rempel', A.A., Zh. Strukt. Khim., 2004, vol. 45, Suppl., pp. 156-162.

13. von Weimarn, P.P., Chem. Rev., 1925, vol. 2, pp. 217242.

14. Volmer, M., Kinetik der Phasenbildung, J.W. Edwards, 1945. Translated under the title Kinetika obrazovaniya novoi sredy, Moscow: Nauka, 1986.

15. Leite, E.R. and Ribeiro, C., Crystallization and Growth of Colloidal Nanocrystals, New York; Dordrecht, Heidelberg; London: Springer, 2012, pp. 36-39.

Translated by V. Glyanchenko 